\title{
Mucocele of a giant inferior turbinate concha bullosa mimics a nasal mass: case report
}

\author{
Kamal Ebeid ${ }^{*}$ (D) and Mohamed H. Askar
}

\begin{abstract}
Background: The concha bullosa is a pneumatized nasal turbinate commonly middle turbinate but that of the inferior turbinate is an uncommon entity. A giant inferior conchal pneumatization with mucocele formation is not reported in the literature till now.

Case presentation: A 17-year-old female patient presented with bilateral severe nasal obstruction. Anterior rhinoscopy and endoscopic examination revealed a giant mass which filled the left nasal cavity completely, pushing the septum to the contralateral side. The paranasal sinus $C T$ showed a mass in the left nasal cavity ballooning the whole nasal cavity with compression of the nasal septum to the right side. MRI was done and the lesion was hyperintense in T2 MRI sequences and hypointense in T1 sequences consistent with a cystic lesion. The patient was consented and prepared for endoscopic resection under general anesthesia. The lesion was completely separated from the nasal septum and the orbit but attached to the lateral nasal wall at the site of origin of the inferior turbinate. Conchoplasty was done and patient follow-up for 9 years is excellent with complete disappearance of all patient symptoms.

Conclusions: Concha bullosa of the inferior turbinate should be considered in the differential diagnosis of nasal tumors, nasal cystic lesions, and preoperative evaluation of endoscopic sinus surgery. Also, a systematic approach for dealing with nasal lesions with thorough examination and radiological review will be of great value in decisionmaking. The anatomy of the paranasal should be thoroughly examined prior to endoscopic sinus surgery to develop treatment strategies and to prevent possible complications.
\end{abstract}

Keywords: Nasal turbinate, Concha bullosa, Nasal concha, Mucocele, Nasal mass, Case report

\section{Background}

The concha bullosa is a pneumatized nasal turbinate commonly middle turbinate but that of the inferior turbinate is an uncommon entity; the concha bullosa of the inferior turbinate can be unilateral or bilateral, isolated, or combined with other turbinate anomalies and commonly asymptomatic [1-3].

Inferior turbinate concha bullosa is a rare entity with a limited number of recorded cases with major manifestations according to our review of literature but concha

\footnotetext{
*Correspondence: Kamal.ebeid@med.tanta.edu.eg
}

Otorhinolaryngology Department, Faculty of Medicine, Tanta University, Tanta, Egypt

\section{Springer Open}

(c) The Author(s). 2021 Open Access This article is licensed under a Creative Commons Attribution 4.0 International License, which permits use, sharing, adaptation, distribution and reproduction in any medium or format, as long as you give appropriate credit to the original author(s) and the source, provide a link to the Creative Commons licence, and indicate if changes were made. The images or other third party material in this article are included in the article's Creative Commons licence, unless indicated otherwise in a credit line to the material. If material is not included in the article's Creative Commons licence and your intended use is not permitted by statutory regulation or exceeds the permitted use, you will need to obtain permission directly from the copyright holder. To view a copy of this licence, visit http://creativecommons.org/licenses/by/4.0/. 
Anterior rhinoscopy and endoscopic examination revealed a giant mass which filled the left nasal cavity completely, pushing the septum to the contralateral side with difficult introduction of the endoscope further than the anterior part of the inferior nasal meatus. The lesion had a smooth pale surface, showed no pulsation, and did not change with the Valsalva maneuver.

The paranasal sinus CT showed a mass in the left nasal cavity ballooning the whole nasal cavity with compression of the nasal septum to the right side and destruction of the inferomedial orbital wall and lateral nasal wall with massive extension into the nasopharynx (Fig. 1). MRI was essential for differential diagnosis of such giant nasal mass before biopsy; the lesion was hyperintense in T2 MRI sequences and hypointense in T1 sequences consistent with a cystic lesion or degenerated tumor (Figs. 2, 3, and 4).

Biopsy as an outpatient procedure was planned but the consistency of the lesion was so hard with difficult processing of tissue samples mimics a boney lesion, so the next step was evaluation under general anesthesia with the possibility of excisional biopsy.

The patient was consented and prepared for endoscopic sinus surgery under general anesthesia; the first step was an endoscopic examination of the lesion with identification of the origin of the lesion using a 4-mm zero-degree endoscope; the lesion was completely separated from the nasal septum and the orbit but attached to the lateral nasal wall at the site of origin of the inferior turbinate; a vertical incision was made on the midline of the anterior wall of the mass with a subsequent gush of mucus fluid; the lesion was divided into the medial

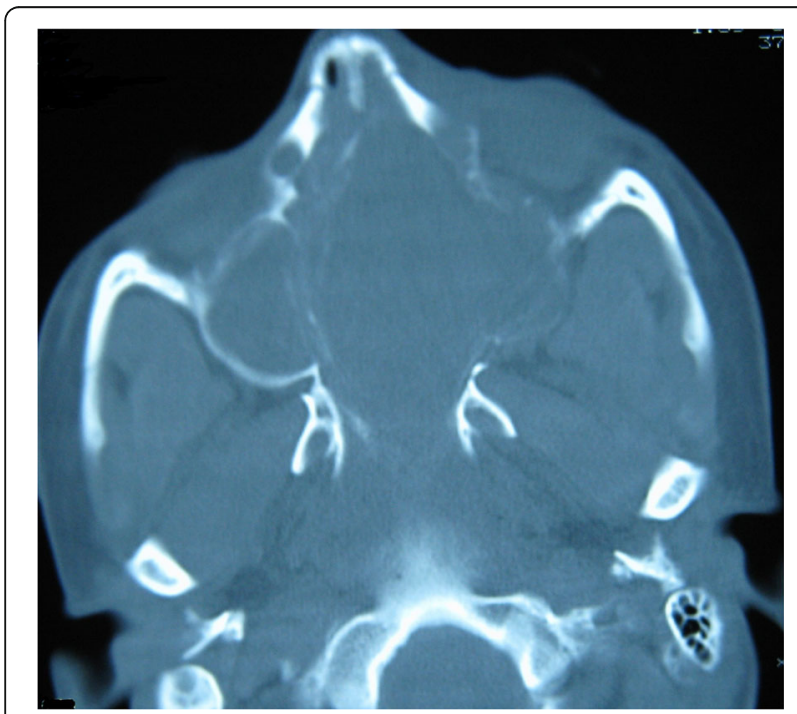

Fig. 1 Axial CT scan of the paranasal sinuses showing a mass in the left nasal cavity ballooning the whole nasal cavity with compression of the nasal septum and orbit and extending to the nasopharynx

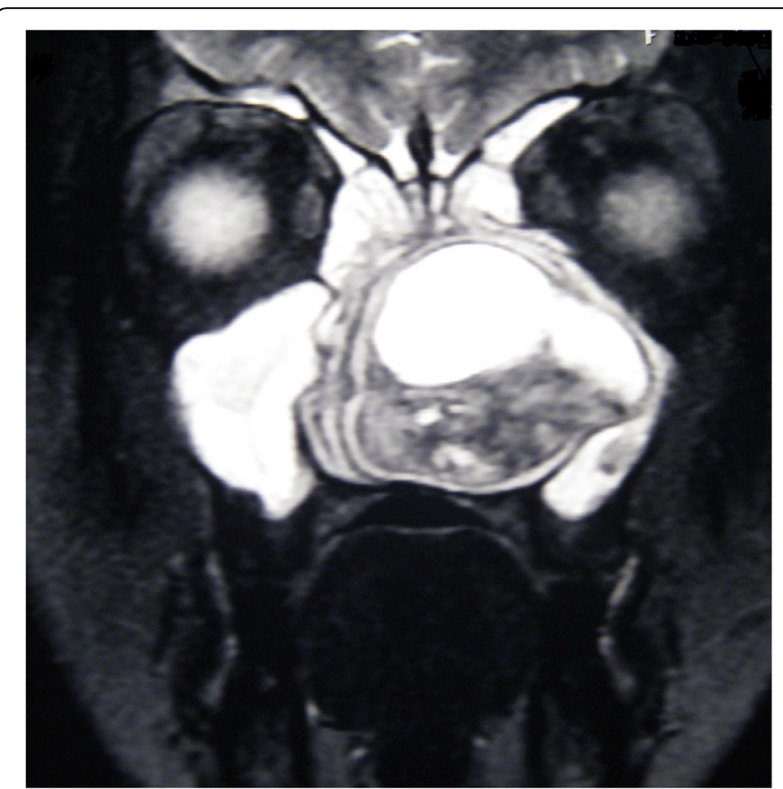

Fig. 2 Coronal MRI with contrast (T2 sequences) of the paranasal sinuses showing a huge lesion with mixed intensities of cystic and solid elements with clearly defined margins

part and lateral part with an apparent identical picture of concha bullosa if inferior turbinate (Fig. 5). Also, septoplasty was done for achieving bilateral patency of the airway. The patient was discharged after $24 \mathrm{~h}$ and nasal pack removed after 2 days with no postoperative complications within a follow-up period of 9 years with complete disappearance of all patient symptoms.

\section{Conclusion}

We think that the present case is a valuable contribution to the literature as a variation that should be considered

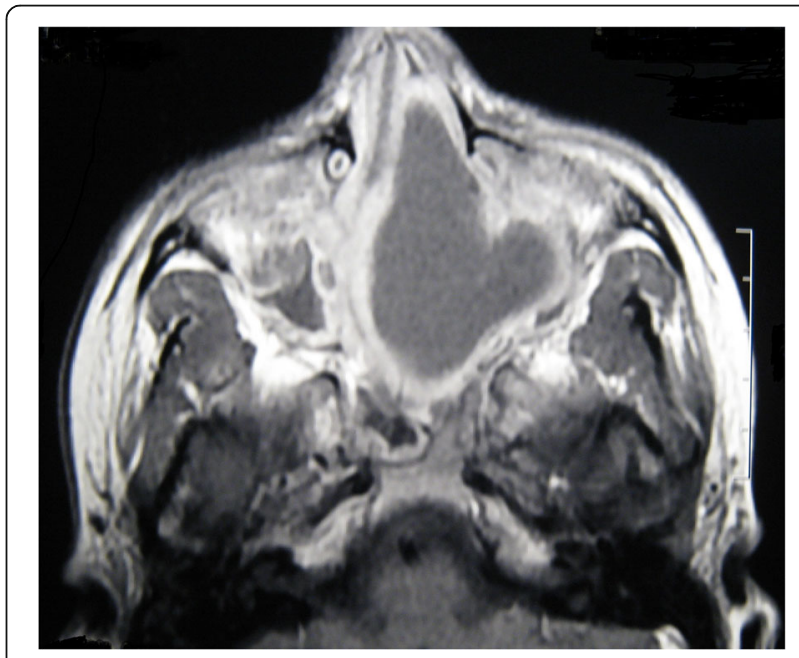

Fig. 3 Axial MRI with contrast (T1 sequences) of the paranasal sinuses showing a huge lesion with hypointense core with enhanced margins 


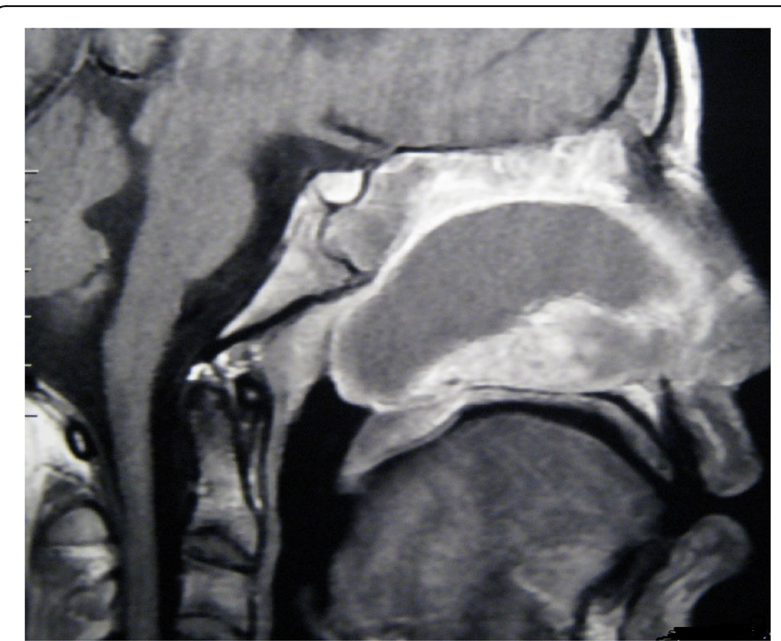

Fig. 4 Sagittal MRI with contrast (T1 sequences) of the paranasal sinuses showing a huge lesion with hypointense core with enhanced margins extending to the nasopharynx

in the differential diagnosis of nasal tumors, nasal cystic lesions, and preoperative evaluation of endoscopic sinus surgery. Also, a systematic approach for dealing with nasal lesions with thorough examination and radiological review will be of great value in decision-making. The anatomy of the paranasal should be thoroughly examined prior to endoscopic sinus surgery to develop treatment strategies and to prevent possible complications.

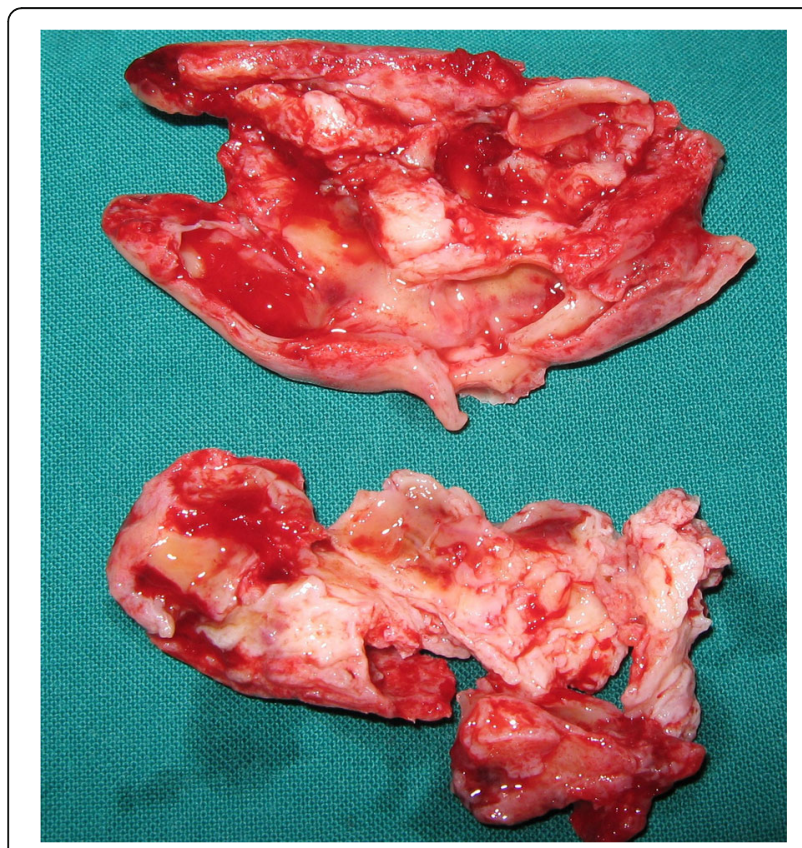

Fig. 5 Specimen after resection showing huge cavity within turbinate tissues

\section{Acknowledgements}

Not applicable.

\section{Authors' contributions}

"KE" is the corresponding author, designed the work, and is the surgeon of the patient while "MA" has drafted the work. All authors have read and approved the final manuscript.

\section{Funding}

No funding issues with this manuscript.

\section{Availability of data and materials}

All data and material are available upon request.

\section{Declarations}

Ethics approval and consent to participate

An ethical approval was obtained from the Research Ethics Committee of the Faculty of Medicine, Tanta University, and the approval code is 34340/ $12 / 20$. Written informed consent was obtained from the patient's parents for participation in this case report.

\section{Consent for publication}

Written informed consent was obtained from the patient's parents for the publication of this case report and accompanying images.

\section{Competing interests}

The authors declare that they have no competing interests.

Received: 14 May 2021 Accepted: 12 June 2021

Published online: 08 July 2021

\section{References}

1. Bolger WE, Butzin CA, Parsons DS (1991) Paranasal sinus bony anatomic variations and mucosal abnormalities: $C T$ analysis for endoscopic sinus surgery. Laryngoscope 101(1):56-64. https://doi.org/10.1288/00005537-1991 01000-00010

2. Sazgar AA, Massah J, Sadeghi M, Bagheri A, Rasool E (2008) The incidence of concha bullosa and the correlation with nasal septal deviation. B-ENT. 4(2):87-91 PMID: 18681204

3. Cukurova I, Yaz A, Gumussoy M, Yigitbasi OG, Karaman Y (2012) A patient presenting with concha bullosa in another concha bullosa: a case report. J Med Case Reports 6(1):87. https://doi.org/10.1186/1752-1947-6-87

4. Bahadir O, Imamoglu M, Bektas D (2006) Massive concha bullosa pyocele with orbital extention. Auris Nasus Larynx. 33(2):195-198. https://doi.org/10.1 016/j.anl.2005.11.007

5. Moideen SP, Mohan M, Arun G (2017) Giant concha bullosa with secondary maxillary sinusitis. Ann Int Med Den Res. https://doi.org/10.21276/aimdr.201 7.3.3.EN1

\section{Publisher's Note}

Springer Nature remains neutral with regard to jurisdictional claims in published maps and institutional affiliations.

\section{Submit your manuscript to a SpringerOpen ${ }^{\circ}$ journal and benefit from:}

- Convenient online submission

- Rigorous peer review

- Open access: articles freely available online

- High visibility within the field

- Retaining the copyright to your article

Submit your next manuscript at $\boldsymbol{\nabla}$ springeropen.com 